\title{
Influence of precursor dose and residence time on the growth rate and uniformity of vanadium dioxide thin films by atomic layer deposition
}

Cite as: J. Vac. Sci. Technol. A 38, 042401 (2020); https://doi.org/10.1116/6.0000152

Submitted: 26 February 2020 . Accepted: 24 April 2020 . Published Online: 15 May 2020

Kham M. Niang (D), Guandong Bai, and John Robertson

\section{COLLECTIONS}

Paper published as part of the special topic on Atomic Layer Deposition (ALD)

Note: This paper is part of the 2021 Special Topic Collection on Atomic Layer Deposition (ALD).
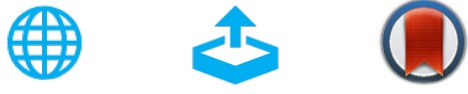

\section{ARTICLES YOU MAY BE INTERESTED IN}

The role of plasma in plasma-enhanced atomic layer deposition of crystalline films

Journal of Vacuum Science \& Technology A 38, 040801 (2020); https://

doi.org/10.1116/6.0000145

Comprehensive characterization of copper oxide atomic layer deposition using water or ozone with enhanced bis-(dimethylamino-2-propoxide) copper delivery

Journal of Vacuum Science \& Technology A 38, 042403 (2020); https://

doi.org/10.1116/6.0000248

\section{Consistency and reproducibility in atomic layer deposition}

Journal of Vacuum Science \& Technology A 38, 020804 (2020); https://

doi.org/10.1116/1.5140603

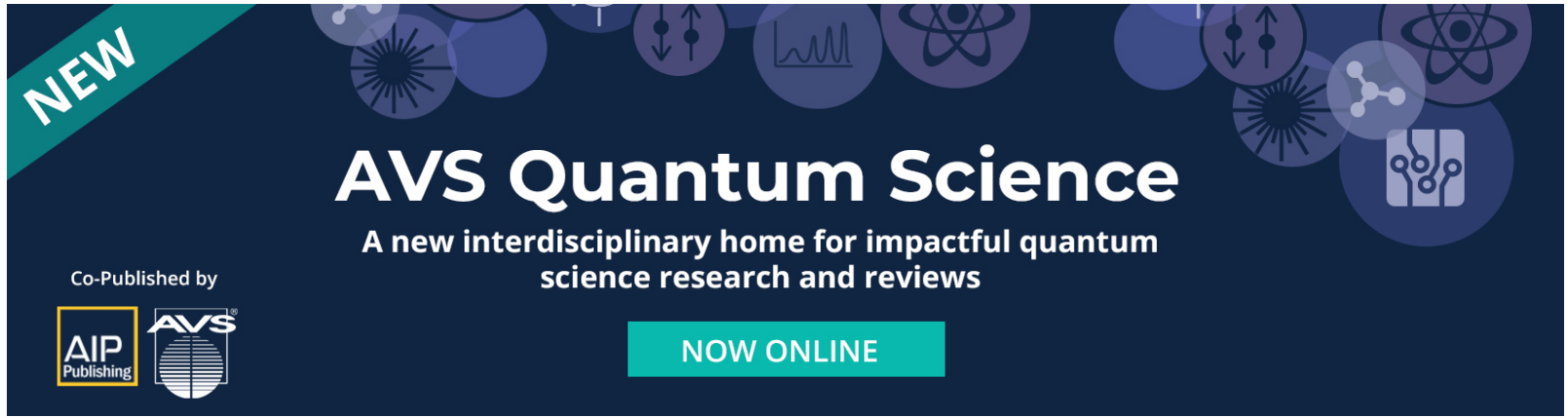




\title{
Influence of precursor dose and residence time on the growth rate and uniformity of vanadium dioxide thin films by atomic layer deposition
}

Cite as: J. Vac. Sci. Technol. A 38, 042401 (2020); doi: $10.1116 / 6.0000152$

Submitted: 26 February 2020 . Accepted: 24 April 2020 .

Published Online: 15 May 2020

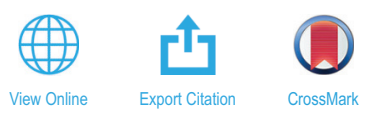

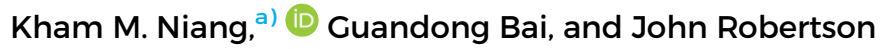

AFFILIATIONS

Department of Engineering, University of Cambridge, 9 JJ Thomson Avenue, Cambridge CB3 OFA, United Kingdom

Note: This paper is part of the 2021 Special Topic Collection on Atomic Layer Deposition (ALD).

a) Author to whom correspondence should be addressed: kmn36@cam.ac.uk

\begin{abstract}
The growth of vanadium dioxide $\left(\mathrm{VO}_{2}\right)$ thin films using tetrakis (ethyl-methyl) amino vanadium (TEMAV) and $\mathrm{H}_{2} \mathrm{O}$ by atomic layer deposition (ALD) has been investigated as a function of the exposure dose and residence time. A novel multiple pulse mode has been employed to mitigate the small deposition rate brought about by the low vapor pressure of TEMAV. Compared to the conventional ALD cycle with a single pulse of precursor, the use of multiple pulsing with very short pulse time allows lower consumption of precursor, but larger exposure dose and longer residence time on the growth surface, resulting in a higher growth rate for a low volatility precursor, while maintaining a good film uniformity across 4 -in. wafers. The Raman analysis and the electrical resistivity modulation of the $\mathrm{VO}_{2}$ thin films show that the films synthesized by the multiple pulse mode is comparable to the films synthesized by the conventional single pulse mode.
\end{abstract}

Published under license by AVS. https://doi.org/10.1116/6.0000152

\section{INTRODUCTION}

Vanadium dioxide $\left(\mathrm{VO}_{2}\right)$ is a highly correlated oxide material that undergoes a sharp metal-insulator transition (MIT) at around $68^{\circ} \mathrm{C}$. ${ }^{1,2}$ The MIT can be triggered thermally, electrically, or optically, thus opening up potential applications in various electronics and optical electronics such as smart windows, ${ }^{3}$ steep slope switches, ${ }^{4,5}$ optical modulators, ${ }^{6}$ sensors, ${ }^{7}$ and tunable capacitors. ${ }^{8}$ $\mathrm{VO}_{2}$ has been synthesized by various deposition techniques such as pulsed laser deposition (PLD), ${ }^{9}$ magnetron sputtering, ${ }^{10}$ e-beam evaporation, ${ }^{11}$ solgel deposition, ${ }^{12}$ and atomic layer deposition (ALD). ${ }^{13}$ Among these, ALD is a very attractive technique due to its precision on stoichiometry arising from the self-limiting growth, its repeatability, and its conformality over a large substrate area. ALD employs alternating pulses of reactants (a chemical precursor and an oxidizer), which are exposed to the substrate where chemisorption takes place. An inert gas purge cycle is employed after pulsing for removing reaction by-products and unreactive precursors, thus resulting in the self-limiting surface reaction. ${ }^{14}$

Different types of precursors have been developed for the ALD of $\mathrm{VO}_{2}$, including $\beta$-diketonate, alkoxide, and alkylamide compounds. Recently, tetrakis (ethyl-methyl) amino vanadium
(TEMAV) has been increasingly used because the synthesized films from this precursor form oxides with vanadium in +4 valency, leading, in principle, to the growth of pure phase $\mathrm{VO}_{2} \cdot{ }^{13,15,16}$ The window of the deposition temperatures for the $\mathrm{VO}_{2}$ deposition using TEMAV as the vanadium precursor is reported to be between 125 and $175^{\circ} \mathrm{C}$. Outside this temperature range, the self-limiting growth mechanism ceases, and the growth rate increases due to the physisorption of the precursor on the substrate at lower temperatures and due to the decomposition of the TEMAV at higher temperatures. ${ }^{15,17}$ For the ALD depositions of $\mathrm{VO}_{2}$ at $150{ }^{\circ} \mathrm{C}$, a saturated growth per cycle (GPC) of $0.5-0.8 \AA /$ cycle has been reported when using $\mathrm{H}_{2} \mathrm{O}$ as the oxidant, ${ }^{15,16}$ whereas a GPC of $0.4-1.0 \AA$ / cycle has been reported when using $\mathrm{O}_{3}$ as the oxidant. ${ }^{13,16}$

The low vapor pressure of TEMAV [13 Pa at $25^{\circ} \mathrm{C}$ (Ref. 18)] at a typical growth temperature is a fundamental problem for the ALD of $\mathrm{VO}_{2}$. In ALD, the GPC of a film indicates that a reaction saturation is achieved. However, deviation from the saturated growth was sometimes reported due to parasitic reactions, ${ }^{19}$ and sometimes such a deviation was created deliberately by changing process conditions to understand the process better. ${ }^{20}$ Such investigations have been reported for alumina $\left(\mathrm{Al}_{2} \mathrm{O}_{3}\right)$, which is probably 
the most widely investigated ALD material, and its precursor trimethylaluminium (TMA) has a high vapor pressure $\left(1.2 \mathrm{kPa}\right.$ at $20^{\circ}$ C). ${ }^{14}$ Matero et al. ${ }^{19}$ have reported that $\mathrm{Al}_{2} \mathrm{O}_{3}$ has a higher GPC $(1.2 \AA)$ when a large water dose was used, compared to a saturated GPC $(\sim 1.1 \AA)$. Likewise, Henn-Lecordier et al. ${ }^{21}$ have shown that an excess dose of water can introduce parasitic reactions in addition to the fundamental half-reactions for $\mathrm{ALD} \mathrm{Al}_{2} \mathrm{O}_{3}$. On the other hand, Salami et al. ${ }^{22}$ have shown that excess TMA does not increase the GPC due to the self-saturating nature of the ALD process. However, surprisingly, underdosing of TMA increases the GPC significantly, up to $2.84 \AA$, which is attributed to the stronger adsorption of water molecules on the growth surface where the alkyl ligand is lacking, opening a pathway for the parasitic reactions. In the development of $\mathrm{VO}_{2}$, such a detailed study of the ALD process has not been fully investigated. Achieving higher GPC with nonstandard pulsing scheme without compromising the film's quality would be highly desirable.

Therefore, in this work, a novel method employing multiple pulsing of TEMAV is investigated and its effect on the growth rate and thickness uniformity across 4 -in. wafers is reported. In order to make sure this new scheme of TEMAV pulsing does not compromise the quality of the films, the structural and electrical properties of the films have been characterized and compared with those from the standard ALD depositions, i.e., single pulsing of TEMAV.

\section{EXPERIMENTAL DETAILS}

$\mathrm{VO}_{2}$ thin films were deposited using a cross-flow wafer scale ALD reactor (Savannah ALD100 system from Cambridge Nanotech) on n-type $\mathrm{Si}(100)$ wafers (resistivity $=0.015-0.025 \Omega \mathrm{cm}$ ) and thermal oxide on silicon $\left(\mathrm{SiO}_{2} / \mathrm{Si}\right)$ substrates. Figure 1 (a) shows the schematic of the single pulse (SP) and multiple pulse (MP) mode employed in this experiment. The SP mode is the conventional ALD method with the following sequence: TEMAV pulse/purge $/ \mathrm{H}_{2} \mathrm{O}$ pulse/purge are denoted by $\mathrm{t} 1 / \mathrm{t} 2 / \mathrm{t} 3 / \mathrm{t} 4$, respectively. In the $\mathrm{MP}$ mode, very short TEMAV pulses are repeated, and the sequence of one ALD cycle is as follows: (TEMAV pulse-delay time) repeat $\mathrm{M}$ times/purge $/ \mathrm{H}_{2} \mathrm{O}$ pulse/purge, which are denoted by $(\mathrm{t} 1-\mathrm{d}) \times \mathrm{M} / \mathrm{t} 2 / \mathrm{t} 3 / \mathrm{t} 4$. Here, $\mathrm{M}$ varies from 3 to 20 . Figures $1(\mathrm{~b})$ and $1(\mathrm{c})$ show the ALD chamber pressure during one cycle of SP and MP modes, respectively. For illustration purposes, the $\mathrm{N}_{2}$ flow was switched off due to the low vapor pressure of TEMAV. However, at all times during the deposition, the nitrogen flow was kept constant at 20 standard cubic centimeters per minute $(\mathrm{sccm})$ reaching a chamber pressure of $\sim 0.1$ Torr. The deposition temperature was kept constant at $150^{\circ} \mathrm{C}$. The TEMAV cylinder was heated to $105^{\circ} \mathrm{C}$, which yields a vapor pressure of $\sim 1$ Torr.

As shown in Fig. 1(b), the chamber pressure increases by $\sim 0.13$ Torr (from the background level) with a $0.05 \mathrm{~s}$ water pulse, since its vapor pressure is very high. In contrast, only a small increase in chamber pressure appears with a $0.2 \mathrm{~s}$ TEMAV pulse in SP mode [ 0.02 Torr as shown in Fig. 1(b)], and an even smaller increase with a $0.02 \mathrm{~s}$ TEMAV pulse in MP mode [ $\sim 004$ Torr as shown in Fig. 1(c)]. A typical ALD pulse (SP mode) produces a sharp rise in pressure to a maximum peak and then tails off to the background level. In the MP mode, broader peak is observed (a)

Single pulse (SP) mode

$\left.\left.\begin{array}{c}\text { TEMAV } \\ \text { pulse, } t 1\end{array} \rightarrow \begin{array}{c}\text { Purge, } \\ t 2\end{array}\right] \begin{array}{c}\mathrm{H}_{2} \mathrm{O} \\ \text { pulse, } \mathrm{t} 3\end{array}\right)\left(\begin{array}{c}\text { Purge, } \\ \mathrm{t} 4\end{array}\right.$

Multiple pulse (MP) mode

\begin{tabular}{|c|c|c|c|c|}
\hline $\begin{array}{r}\text { TEMAV } \\
\text { pulse, t1 }\end{array}$ & $\begin{array}{c}\text { Delay, } \\
\text { d }\end{array}$ & $\begin{array}{l}\text { Purge, } \\
\text { t2 }\end{array}$ & $\begin{array}{c}\mathrm{H}_{2} \mathrm{O} \\
\text { pulse, t3 }\end{array}$ & $\begin{array}{c}\text { Purge, } \\
\text { t4 }\end{array}$ \\
\hline \multicolumn{2}{|c|}{ x M cycles } & cycl & & \\
\hline
\end{tabular}

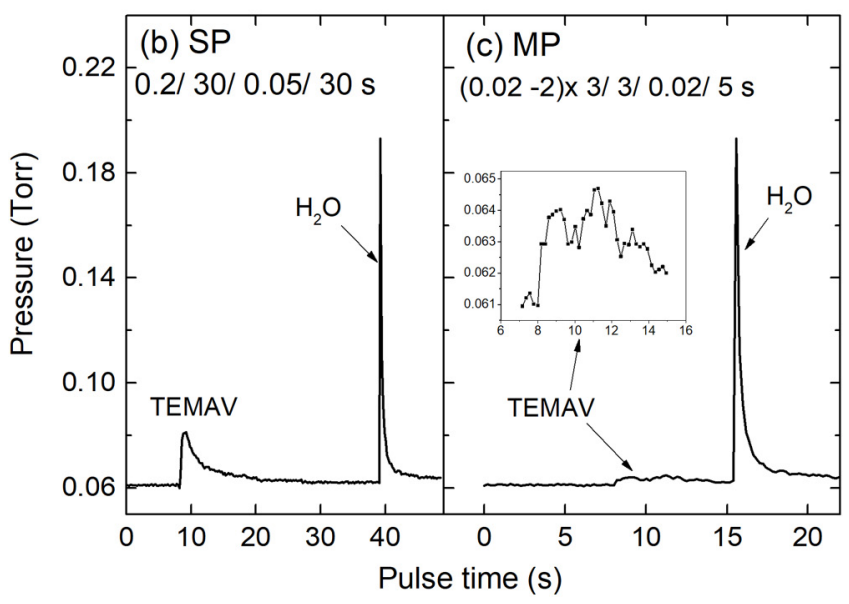

FIG. 1. (a) Typical sequence of the SP and MP modes of the ALD process. t1 and $\mathrm{t} 3$ denote the pulse time, and $\mathrm{t} 2$ and $\mathrm{t} 4$ denote the purge time of the TEMAV and $\mathrm{H}_{2} \mathrm{O}$, respectively. d denotes the delay time between TEMAV multiple pulses, which is repeated $\mathrm{M}$ times. $\mathrm{N}$ denotes the number of ALD cycles. The ALD chamber pressure during one cycle of (b) the SP mode using sequence $t 1 / 2 / t 3 / t 4$ of $0.2 / 30 / 0.05 / 30 \mathrm{~s}$ and (c) the MP mode using sequence $(\mathrm{t} 1-\mathrm{d}) \times \mathrm{M} / \mathrm{t} 2 / \mathrm{t} / \mathrm{t} / 4$ of $(0.02-2) \times 3 / 3 / 0.02 / 5 \mathrm{~s}$. No $\mathrm{N}_{2}$ flow was used for this illustration due to the low vapor pressure of TEMAV; the inset in (c) is the zoom in of the TEMAV pulse.

depending on the number of repeated pulses. Despite a small increase in pressure, the individual peak for the three TEMAV pulses can be identified at $\sim 9,11$, and $13 \mathrm{~s}$ [inset of Fig. 1(c)].

The precursor exposure dose is calculated by integrating the area under the curve of the pressure profile (see supplementary material for details). ${ }^{32}$ Special attention is paid when determining the dose for the TEMAV because, in the vapor draw method used in this work, the first pulse is very high due to the pressure build up in the chemical bubbler after heating it to $105^{\circ} \mathrm{C}$. Therefore, the initial ten pulses have been processed before the pressure for the TEMAV is recorded. A TEMAV pulse results in the transient pressure increase of $\sim 0.02$ Torr in the SP mode and 0.004 Torr in the MP mode. In comparison, an increase in transient pressure $\sim 0.13$ Torr occurs for a $\mathrm{H}_{2} \mathrm{O}$ pulse. 
Since the ALD deposition temperature is low, the as-deposited $\mathrm{VO}_{2}$ thin films are amorphous, and a postdeposition annealing is required to produce polycrystalline films. Therefore, development of $\mathrm{VO}_{2}$ by ALD is a two-step process. The postdeposition annealing was performed in a $1 \mathrm{in}$. diameter quartz tube furnace. Typically, the $\mathrm{VO}_{2}$ thin films were annealed at $450{ }^{\circ} \mathrm{C}$, at a pressure of 0.1 Torr in an $\mathrm{O}_{2} / \mathrm{Ar}$ ambient, for times between $30 \mathrm{~min}$ and a few hours depending on the film thickness. ${ }^{23}$ At higher temperatures and/or higher $\mathrm{O}_{2}$ partial pressures, vanadium oxides with higher oxidation states (for example, $\mathrm{V}_{2} \mathrm{O}_{5}$ ) are formed. ${ }^{16}$

The structural and optical properties of the $\mathrm{VO}_{2}$ films were analyzed at room temperature using spectroscopic ellipsometry (J.A. Woollam M-2000), atomic force microscopy, and Raman spectroscopy (Renishaw InVia). The resistivity modulation was investigated on a Keithley 4200 parameter analyzer using a fourpoint probe measurement and varying the temperatures between 25 and $120^{\circ} \mathrm{C}$.

\section{RESULTS}

\section{A. Growth rate}

First, the ALD growth saturation using the SP mode was assessed by increasing the pulse and purge times of both reactants. Figure 2(a) shows the GPC as a function of pulse time which was varied between 0.2 and $5 \mathrm{~s}$ for TEMAV and 0.02 and $0.2 \mathrm{~s}$ for $\mathrm{H}_{2} \mathrm{O}$. The times for the pulse sequence $\mathrm{t} 1 / \mathrm{t} 2 / \mathrm{t} 3 / \mathrm{t} 4$ are $x / 30 / 0.05 /$ $30 \mathrm{~s}$ when TEMAV pulse time is varied and $3 / 30 / x / 30 \mathrm{~s}$ when $\mathrm{H}_{2} \mathrm{O}$ pulse time is varied. For TEMAV precursor, the GPC of
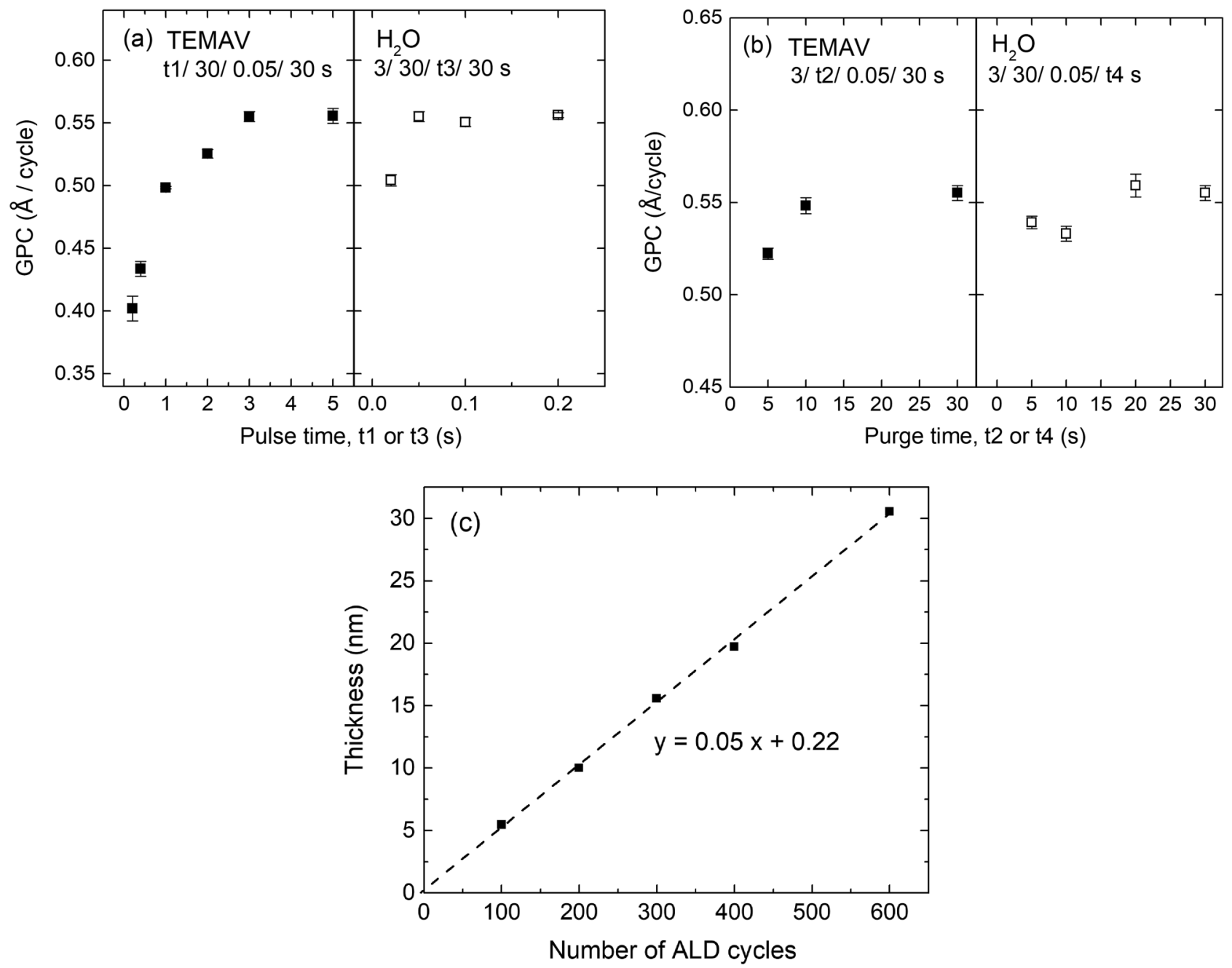

FIG. 2. Examination of ALD growth saturation using the SP mode: the GPCs of $\mathrm{VO}_{2}$ thin films as a function of (a) pulse time and (b) purge time of TEMAV and $\mathrm{H}_{2} \mathrm{O}$. $\mathrm{t} 1 / \mathrm{t} 2 /$ t3/t4 denote the pulse and purge times of the ALD sequences. (c) Film thickness as a function of the number of ALD cycles, and the linear fitting demonstrates a growth rate of $0.5 \AA$ A cycle. The substrate temperature during ALD was maintained at $150^{\circ} \mathrm{C}$. 
$0.40 \AA /$ cycle is achieved with a $0.2 \mathrm{~s}$ pulse time. The GPC increases significantly with increasing pulse times up to $3 \mathrm{~s}$ and it saturates between 3 and $5 \mathrm{~s}$ to a value of $0.55 \AA /$ cycle. The GPC increase is more gradual with $\mathrm{H}_{2} \mathrm{O}$ pulses. A GPC of $0.50 \AA$ /cycle is achieved with a $0.02 \mathrm{~s}$ pulse time and it increases to the saturated level of $0.55 \AA /$ cycle with a 0.05 s pulse time. The $\mathrm{VO}_{2}$ films were deposited on across 4-in. wafers and thickness measured at 9 points with $10 \mathrm{~mm}$ apart between points. The GPC values shown here are the average thickness, and the thickness variation is shown as the error bar. The thickness variation is very small except for the data of the TEMAV pulse time of $0.2 \mathrm{~s}$ which is the shortest pulse time used in the experiment.

Figure 2(b) shows the GPC as a function of purge time while pulsing the TEMAV and $\mathrm{H}_{2} \mathrm{O}$ for $3 \mathrm{~s}$ and $0.05 \mathrm{~s}$, respectively. When the TEMAV purge time is varied, the $\mathrm{H}_{2} \mathrm{O}$ purge time is kept constant at $30 \mathrm{~s}$ and vice versa. The GPC of TEMAV decreases only minimally when the purge time was reduced from 30 to $10 \mathrm{~s}$; however, a GPC reduction is significant for the $5 \mathrm{~s}$ purge time. The effect of reducing the purge time for $\mathrm{H}_{2} \mathrm{O}$ on the GPC is also minimal. Even though a purge time of $30 \mathrm{~s}$ is mostly used for SP modes in this work, the results in Fig. 2(b) indicates the possibility of reducing the purge time which is desirable to improve process throughput. Figure 2(c) shows the film thickness as a function of the number of ALD cycles using a sequence of 3/30/0.05/30 s. The dashed line is the linear fitting of the thickness data, demonstrating a GPC of $0.5 \AA /$ cycle.

The GPC reported here is on the lower end of the range of GPC reported in the literature, where TEMAV is used as the precursor and $\mathrm{H}_{2} \mathrm{O}$ as the oxidant and at a temperature of $150^{\circ} \mathrm{C}$. In fact, a wide range of GPC has been reported for the growth of $\mathrm{VO}_{2}$ in the literature. Blanquart et al. ${ }^{15}$ reported a GPC of $0.7 \AA$ /cycle on the films deposited using a F-120 ALD reactor (ASM Microchemistry Ltd.), whereas Currie et al. ${ }^{23}$ reported $\sim 0.8-$ $0.9 \AA$ Acycle using a Savannah ALD system (Cambridge Nanotech). On the other hand, Premkumar et al. ${ }^{16}$ reported $0.3-0.4 \AA /$ cycle which was not-saturated, when using an EX system (Tokyo Electron Ltd.).

Next, the ALD growth using the MP mode was investigated. Figure 3(a) shows the GPC as a function of TEMAV pulse times which were varied between 0.06 and $0.3 \mathrm{~s}$, which is calculated from the number of repeated TEMAV pulses (indicated by M3, M6, etc.), multiplied with the pulse time of $0.02 \mathrm{~s}$. The $\mathrm{H}_{2} \mathrm{O}$ pulse and purge times are 0.02 and $5 \mathrm{~s}$, respectively. The total TEMAV purge time is also $5 \mathrm{~s}$, with a $2 \mathrm{~s}$ delay between repeated TEMAV pulses. The schematic of the MP was shown in Fig. 1(a). The GPC of $0.42 \AA /$ cycle is achieved with a $0.06 \mathrm{~s}$ pulse time (M3). The GPC increases almost linearly with increasing pulse times up to $0.24 \mathrm{~s}$ (M12) and it begins to saturate at $0.30 \mathrm{~s}$ (M15) at a value of $0.65 \AA /$ cycle. Upon further increasing the number of pulses to 20 (M20), the GPC decreases to $0.63 \AA$ Acycle with the accompanying large thickness variation as shown by the error bar. This indicates a limit to the number of multiple pulses that can be used. There is also a window for the smallest thickness variation between M6 and M10, and outside of this window the thickness variation is significantly larger.

Figure 3(b) shows the GPC as a function of purge time while pulsing the TEMAV and $\mathrm{H}_{2} \mathrm{O}$ for 0.16 (M8) and $0.05 \mathrm{~s}$,
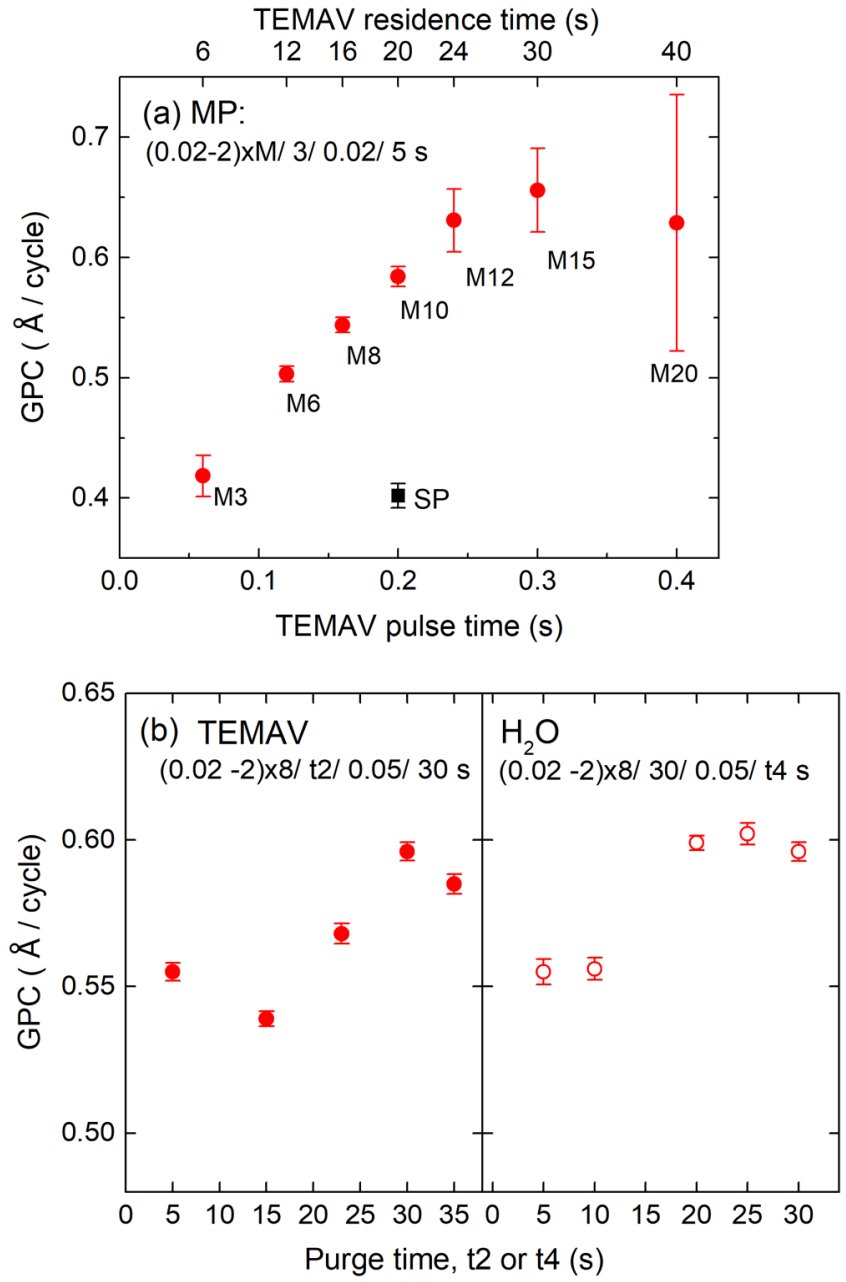

FIG. 3. GPCs of $V_{2}$ thin films as a function of (a) TEMAV pulse time and (b) purge time in the MP mode. For comparison, GPC with $0.2 \mathrm{~s}$ pulse time in SP mode is also plotted in (a). The ALD sequence in the MP mode is $(t 1-d) \times M /$ $\mathrm{t} 2 / \mathrm{t} 3 / \mathrm{t} 4$, where $\mathrm{t} 1$ and $\mathrm{t} 3$ denote pulse time, $\mathrm{t} 2$ and $t 4$ denote purge time, $d$ denotes delay time between TEMAV pulses, and $\mathrm{M}$ denotes the number of repeated pulses.

respectively. While the TEMAV purge time varies, the $\mathrm{H}_{2} \mathrm{O}$ purge time is kept constant at $30 \mathrm{~s}$ and vice versa. In general, the GPC of both TEMAV and $\mathrm{H}_{2} \mathrm{O}$ shows an increasing trend, and the GPC saturates around 25-30 s for TEMAV and $20 \mathrm{~s}$ for $\mathrm{H}_{2} \mathrm{O}$.

\section{B. Wafer uniformity}

Figure 4 shows the uniformity across a 4 -in. wafer. A very good uniformity is obtained for the SP mode [Fig. 4(a)] at the pulse time $0.4-5 \mathrm{~s}$. The highest uniformity is achieved for the pulse time between 1 and $3 \mathrm{~s}(99.8 \%)$. The uniformity is slightly lower in the MP mode [Fig. 4(b)], for M3, the GPC decreases at around $6 \mathrm{~cm}$, achieving a uniformity $95.9 \%$. For M6-M8, the thickness 

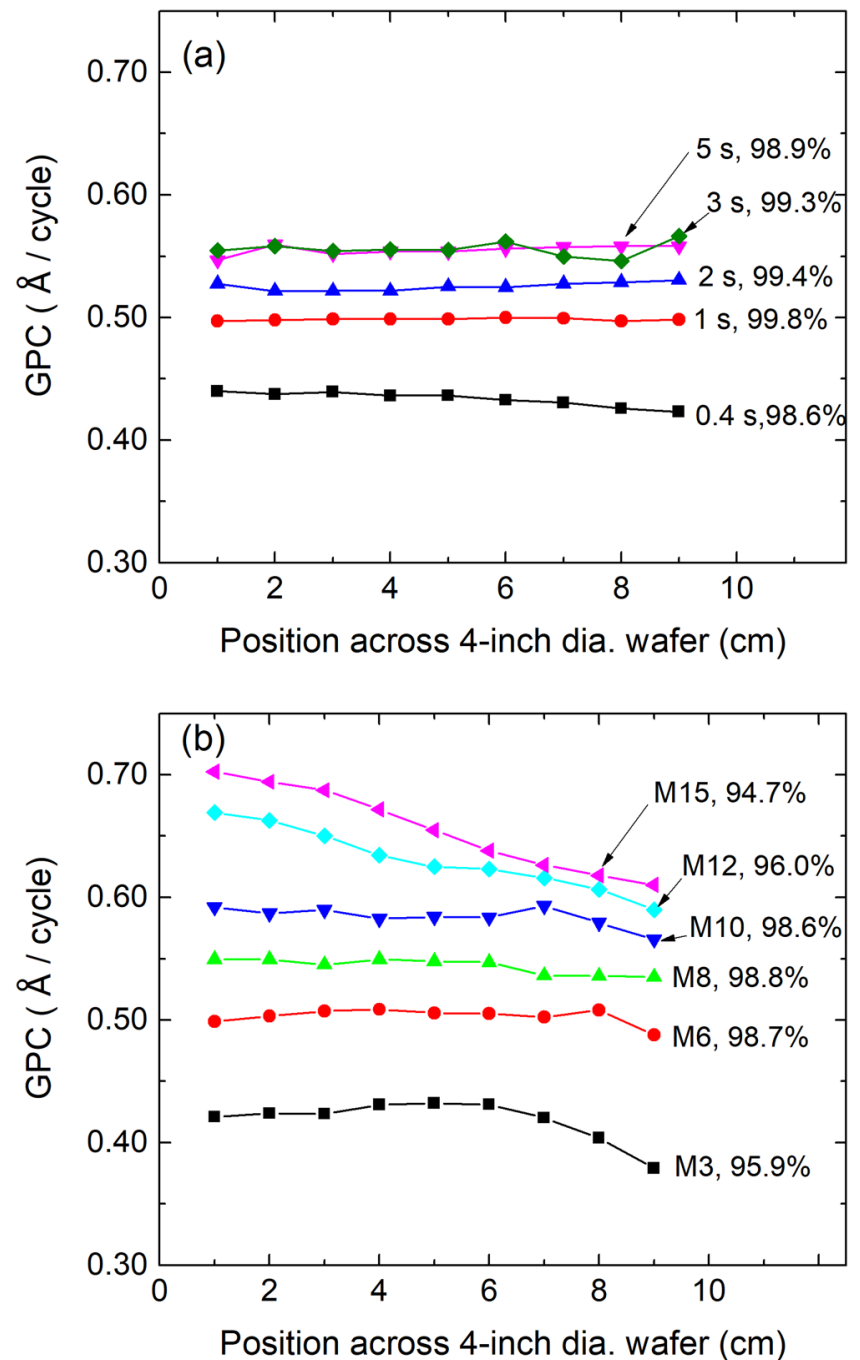

FIG. 4. GPC of $\mathrm{VO}_{2}$ thin films across a 4-in. wafer for (a) single pulse mode and (b) multiple pulse mode. For each sample, the pulse time (in SP) and the number of repeated pulses, M (in MP), together with the film thickness uniformity are shown.

uniformity reaches $\sim 99 \%$. Further increasing the TEMAV pulses deteriorates the uniformity again to $~ 95 \%$ for M12 and M15. A significant gradient from left to right across the wafer corresponds to the direction of the gas flow from the inlet to the outlet of a crossflow reactor used in this work.

\section{Thin film properties}

Figure 5(a) shows the Raman scattering spectra of the $\mathrm{VO}_{2}$ films produced by MP and SP modes, respectively, which were annealed at $450{ }^{\circ} \mathrm{C}$ at 0.1 Torr in $\mathrm{O}_{2} / \mathrm{Ar}$ for $1 \mathrm{~h}$. The various peaks are observed at $193,223,308,396$, and $617 \mathrm{~cm}^{-1}$, which can be
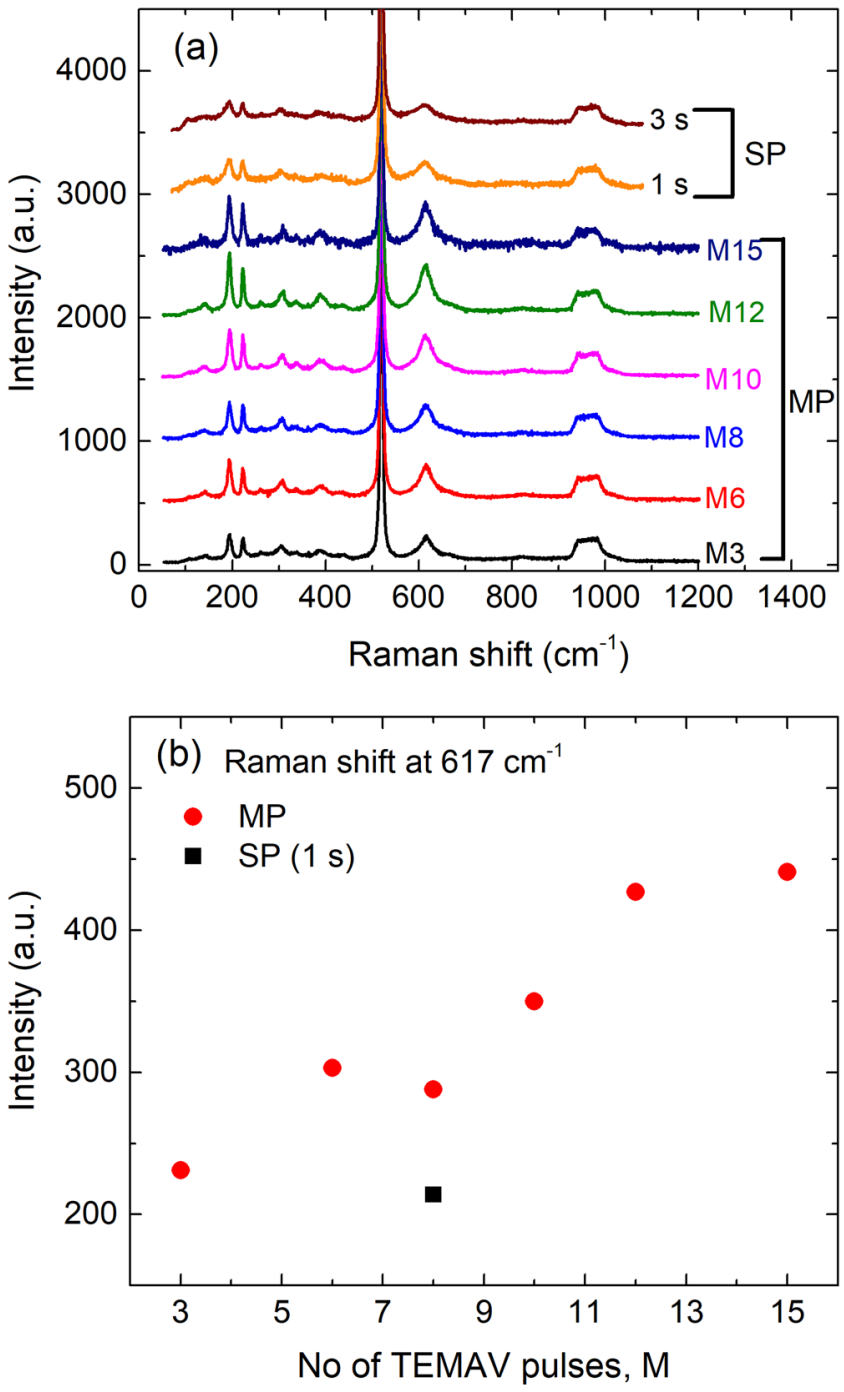

FIG. 5. (a) Overlay of the Raman shift spectra for the annealed $\mathrm{VO}_{2}$ films, which were deposited with different number of pulses in both SP and MP modes and (b) the peak intensity for the Raman shift at $617 \mathrm{~cm}^{-1}$ as a function of the number of pulses in MP mode and $1 \mathrm{~s}$ pulse time of SP mode.

identified as those related to $\mathrm{V}^{4+} .24,25$ The large peak at $\sim 510$ and the broad peak at $\sim 950 \mathrm{~cm}^{-1}$ are related to the silicon substrate. Figure 5(b) shows that the intensity of peaks at $617 \mathrm{~cm}^{-1}$ of the MP mode increases with the number of pulses $M$, which is due to the increase in film thickness, which is $25.1 \mathrm{~nm}$ for M3 and $39.3 \mathrm{~nm}$ for M15. Also shown is the peak of $1 \mathrm{~s}$ pulse time of the SP mode, which is compared with M8 since both have similar thicknesses, $\sim 30 \mathrm{~nm}$. The peak intensity is slightly higher in the MP mode than in the SP mode.

The resistivity values, $\rho$, of the $\sim 30 \mathrm{~nm}$ thick $\mathrm{VO}_{2}$ films after annealing are shown in Fig. 6(a) as a function of temperature. The decrease in resistivity with increasing temperature clearly indicates 


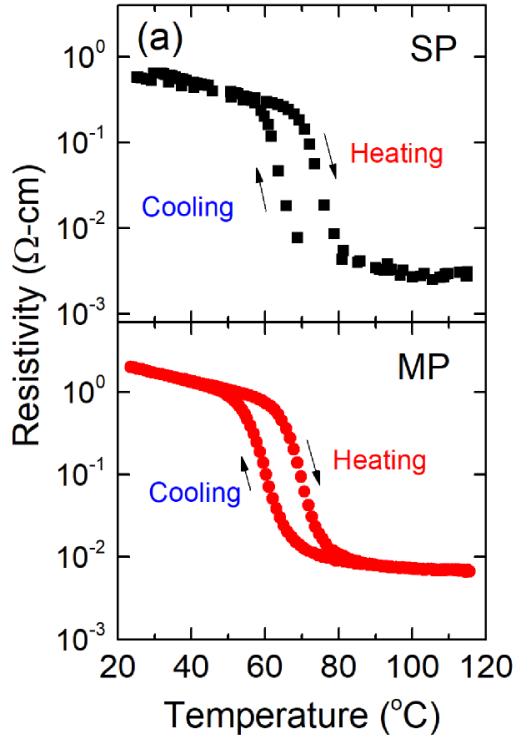

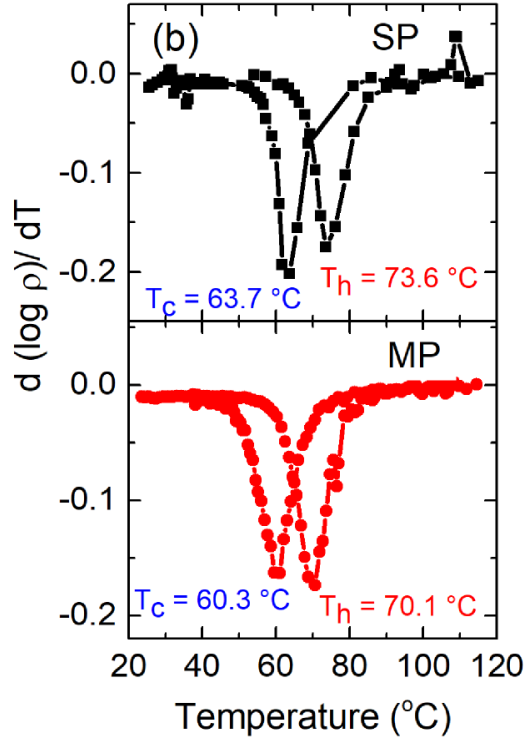

FIG. 6. (a) Resistivity, $\rho$, as a function of temperature and $(b)$ its derivative $[d(\log \rho) / d T]$ for the annealed $\mathrm{VO}_{2}$ of thickness $\sim 30 \mathrm{~nm}$ indicating the transition temperatures during heating cycle $\left(T_{h}\right)$ and cooling cycle $\left(T_{c}\right)$ for depositions in SP and MP modes. a phase change from semiconducting to conducting (MIT). For the SP mode, the phase transition takes place at $\sim 73.6^{\circ} \mathrm{C}$ during a heating cycle and at $\sim 63.7^{\circ} \mathrm{C}$ during a cooling cycle, as shown by the $\mathrm{d}(\log \rho) / \mathrm{dT}$ versus temperature in Fig. 6(b). For the MP mode, the phase transition takes place at $\sim 70.1{ }^{\circ} \mathrm{C}$ during a heating cycle and at $\sim 60.3^{\circ} \mathrm{C}$ during a cooling cycle. The resistivity modulation is slightly higher in the MP mode than in the SP mode ( 300 vs 100). The modulation is in the same order of ALD $\mathrm{VO}_{2}$ films reported by Rampelberg et al. ${ }^{13}$ Compared to the SP mode, the films produced by the MP mode show a more abrupt transition, and the transition temperature $\left(70.7^{\circ} \mathrm{C}\right)$ is also closer to that of the bulk material $\left(68^{\circ} \mathrm{C}\right) .^{2}$ The better electrical performance of films by the MP mode also agrees with the higher intensity of the Raman shift spectra [Fig. 5(b)], since the higher peak intensity is an indicator of the film crystallinity. Therefore, the films deposited using MP modes are slightly superior to the films deposited by the SP modes.

\section{DISCUSSION}

We compare the GPC values between MP and SP modes. In Fig. 3(a), for the same pulse time of $0.2 \mathrm{~s}$, the GPC of MP mode is 1.5 times higher than that of the SP mode ( 0.6 vs $0.4 \AA /$ cycle). In order to explain this, the precursor dose is calculated by integrating the area under the curve of the pressure which is shown in Fig. 1(b). Figure 7 compares the precursor exposure dose as a function of pulse time for both SP and MP modes. The precursor dose is linearly proportional to the pulse time in both cases; however, the gradient of the MP mode is about twice that of the SP mode ( 0.48 vs 0.26 Torr). This indicates that using the MP mode is more effective in increasing the exposure of precursor dose on the growth surface than using the SP mode. This is a key factor for a low volatility precursor. A larger amount of precursor exposure in the MP mode resulted in a higher GPC, as shown in Fig. 3(a). Moreover, when comparing the dose volume, for a pulse time of
$0.2 \mathrm{~s}$, the precursor dose is 0.07 Torr s for the MP mode and 0.16 Torr s for the SP mode. Therefore, MP mode utilizes $\sim 44 \%$ less the precursor dose, but achieves $50 \%$ higher the GPC of $\mathrm{VO}_{2}$.

Cleveland et al. $^{26}$ have previously shown a higher growth of $\mathrm{TiO}_{2}$ by employing multiple pulses of titanium tetraisopropoxide precursor, and the higher growth rate is attributed to the large doses in multiple pulses compared to a single pulse. The advantage of the MP mode is not limited to the higher film growth rate. Aria et $a .^{27}$ have also shown that multiple pulsing of TMA is very effective for the very thin film of $\mathrm{Al}_{2} \mathrm{O}_{3}$ on graphene. They have shown higher nucleation on the surface when MP is used, which is due to the improvement of adhesion of chemicals on the graphene.
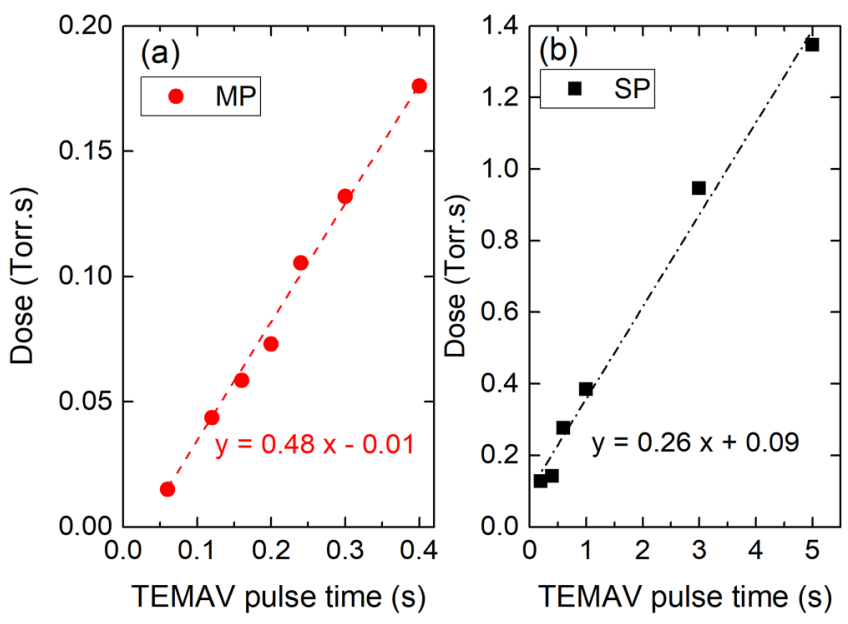

FIG. 7. TEMAV dose as a function of pulse time for (a) MP and (b) SP modes. The linear fittings of the data are shown as dashed/dashed-dotted lines. 
Vanadium oxide has been deposited on nanomaterial like carbon nanotubes for supercapacitor electrodes; ${ }^{28}$ therefore, it can be expected that the multiple pulsing of TEMAV would be particularly suitable for coating nanomaterials.

One notable difference between the MP mode used in this work and that mentioned in the above references ${ }^{26,27}$ is that the MP mode in those works are a multiple of single pulses, thus increasing the chemical consumption proportionally. In our case, since the pulse time in the MP mode is a tenth of the SP mode $(0.02 \mathrm{~s}$ for MP and $0.2 \mathrm{~s}$ for SP), resulting in a much smaller consumption of TEMAV in the MP mode (up to M8). It can be said that the MP mode is effectively an under-dosing of the TEMAV.

Previously, Salami et al. ${ }^{22}$ have shown that under-dosing of TMA surprisingly increases the GPC of $\mathrm{Al}_{2} \mathrm{O}_{3}$ to $2.84 \AA$ /cycle from the typical $1.1 \AA /$ cycle. The high growth rate was attributed to the stronger adsorption of water molecules. ${ }^{22}$ Similar results observed in the present work indicates that under-dosing works for precursors with both small size of alkyl ligands (in TMA) and large size of alkylamide ligand (in TEMAV). Since reduced growth rate has been observed for large precursor molecules due to steric hindrances, ${ }^{29}$ it seems there is no advantage in using large precursor dose as was used in the SP mode. This makes the under-dosing of TEMAV by the MP method for the $\mathrm{VO}_{2}$ growth very attractive since it does not waste expensive chemical while still achieving higher GPC than the conventional SP mode.

The trade-off of using the MP mode will be the longer processing time for the TEMAV half cycle. For example, for the saturated growth of $\mathrm{VO}_{2}$, the TEMAV half cycle takes $33 \mathrm{~s}$ in the SP mode (pulse $3 \mathrm{~s}$ /purge $30 \mathrm{~s}$ ), and to achieve the same growth rate by the MP mode, it takes $\sim 46 \mathrm{~s}$ ((pulse $0.02 \mathrm{~s}$ then delay $2 \mathrm{~s}) \times$ repeat 8 times/purge $30 \mathrm{~s})$. Therefore, due to the delay between successive pulses, the MP mode has long exposure time (residence time) as
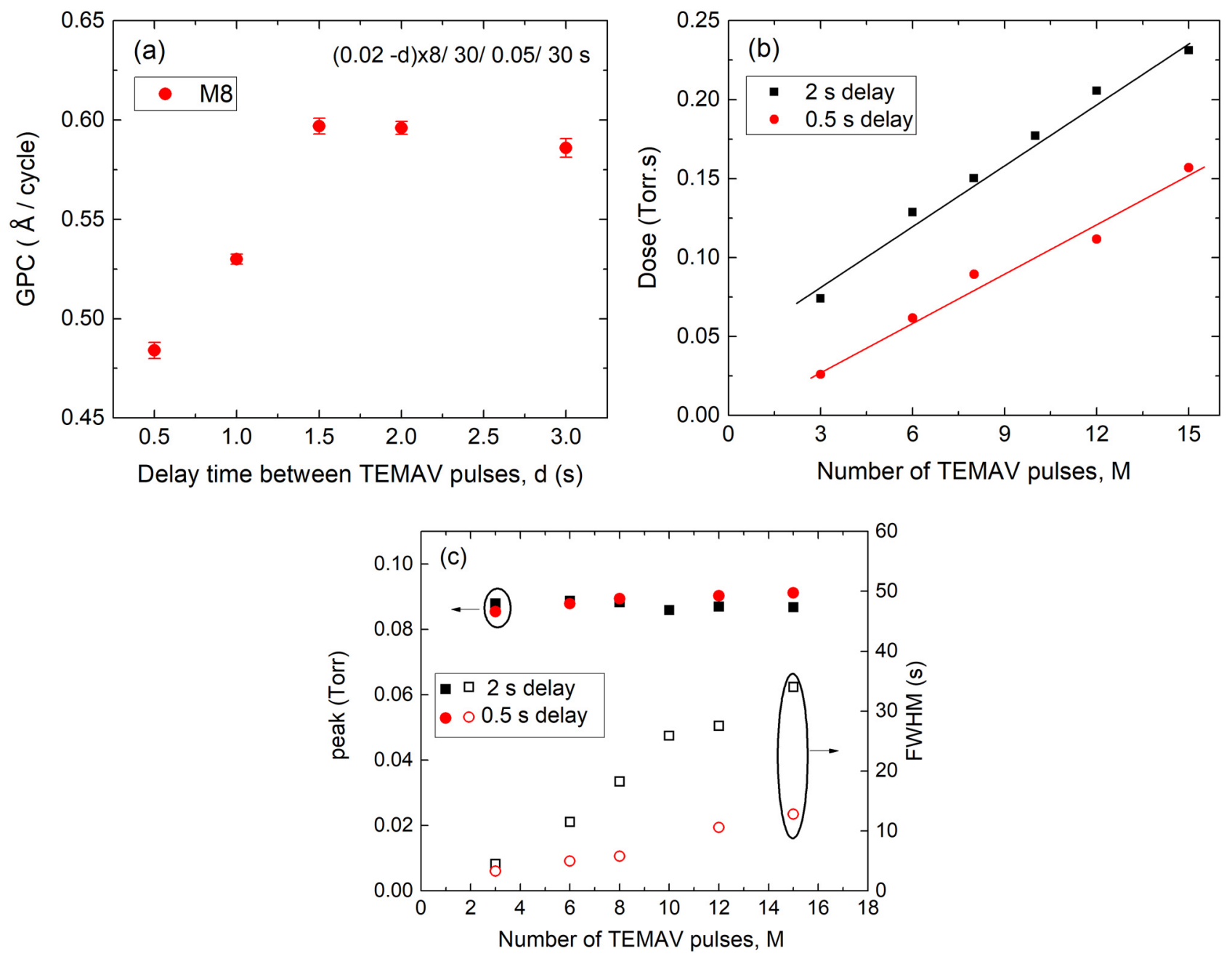

FIG. 8. (a) GPC as a function of delay time between TEMAV pulses for M8. (b) Comparing the calculated TEMAV dose between the delay times of 0.5 and $2 \mathrm{~s}$ for M 3 to M15 (MP modes), and (c) the corresponding peak and FWHM of the TEMAV dose shown in (b). 
shown in Fig. 3(a) (top axis). In an effort to decrease the processing time in the MP mode, the GPC is plotted as a function of delay time between multiple pulses of TEMAV as shown in Fig. 8(a), which shows that the delay time could not be reduced much (minimum $1.5 \mathrm{~s}$ ) in order to still maintain the growth rate.

To further investigate the delay time, the precursor dose was calculated for a series of multiple pulses (M3-M15) for the delay times of 2 and $0.5 \mathrm{~s}$. The pressure profiles are shown in the supplementary material (Fig. S1). ${ }^{32}$ As expected, as shown in Fig. 8(b), the doses for the MP mode with $2 \mathrm{~s}$ delay are higher than those with $0.5 \mathrm{~s}$ delay, agreeing with the GPC. Since the dose is estimated by integrating the area under the pressure curve (Fig. 1), it consists of two components: the peak and the full width at half maximum (FWHM). As shown in Fig. 8(c), the peak of pulses is very similar, but the FWHM increases with the number of pulses. It should be noted that the peak remains the same because the pulse time used in the MP mode is kept constant at $0.02 \mathrm{~s}$, while the pulse width increases according to how often it is repeated. On the contrary, in the conventional SP mode, if the pulse time is increased, the peak increases and the FWHM decreases accordingly. ${ }^{30}$ Therefore, the high growth rate by the MP mode can be attributed to the higher dose, which in turn can be attributed to the longer residence time (or) exposure time.

Since the MP mode would be particularly attractive for coating the $\mathrm{VO}_{2}$ on nanomaterials, and since the required film thicknesses are getting smaller and smaller, ${ }^{31}$ it is expected that the advantages of the MP mode would outweigh the long processing time that is required in the deposition of $\mathrm{VO}_{2}$.

\section{CONCLUSIONS}

In summary, multiple pulsing of TEMAV for short pulse time has been investigated, resulting in a condition of underdosing of the precursor, thus reducing the consumption of an expensive chemical. The main advantage of the MP mode is the higher growth rate compared to the SP mode, which can be explained by the higher precursor dose and longer residence time of the precursor on the growth surface. The thickness uniformity and quality of the films deposited by the MP mode are comparable to that produced by the conventional ALD SP mode.

\section{ACKNOWLEDGMENT}

The financial support from the European Union's Horizon 2020 Research and Innovation Program PHASE-CHANGE SWITCH (Grant Agreement No. 737109) is acknowledged.

\section{REFERENCES}

${ }^{1}$ F. J. Morin, Phys. Rev. Lett. 3, 34 (1959).
${ }^{2}$ C. N. Berglund and H. J. Guggenheim, Phys. Rev. 185, 1022 (1969).

${ }^{3}$ I. Hamberg and C. G. Granqvist, J. Appl. Phys. 60, 123 (1986).

${ }^{4}$ W. A. Vitale, C. F. Moldovan, M. Tamagnone, A. Paone, A. Schuler, and A. M. Ionescu, IEEE Electron Device Lett. 36, 972 (2015).

${ }^{\mathbf{5}}$ G. Stefanovich, A. Pergament, and D. Stefanovich, J. Phys. Condens. Matter 12, 8837 (2000).

${ }^{6}$ M. Maaza, D. Hamidi, A. Simo, T. Kerdja, A. K. Chaudhary, and J. B. K. Kana, Opt. Commun. 285, 4 (2012).

${ }^{7}$ B. Hu, Y. Ding, W. Chen, D. Kulkarni, Y. Shen, V. V. Tsukruk, and Z. L. Wang, Adv. Mater. 22, 5134 (2010).

${ }^{8}$ W. A. Vitale, Sens. Actuators A Phys. 241, 9 (2016).

${ }^{9}$ D. H. Kim and H. S. Kwok, Appl. Phys. Lett. 65, 3188 (1994).

${ }^{10}$ Y. Shigesato, M. Enomoto, and H. Odaka, Jpn. J. Appl. Phys. 39, 6016 (2000).

${ }^{11}$ J. F. De Natale, P. J. Hood, and A. B. Harker, J. Appl. Phys. 66, 5844 (1989).

${ }^{12}$ B.-G. Chae, H.-T. Kim, S.-J. Yun, B.-J. Kim, Y.-W. Lee, D.-H. Youn, and K.-Y. Kang, Electrochem. Solid State Lett. 9, C12 (2006).

${ }^{13}$ G. Rampelberg, M. Schaekers, K. Martens, Q. Xie, D. Deduytsche, B. De Schutter, N. Blasco, J. Kittl, and C. Detavernier, Appl. Phys. Lett. 98, 162902 (2011).

${ }^{14}$ S. George, Chem. Rev. 110, 111 (2010).

${ }^{15}$ T. Blanquart et al., RSC Adv. 3, 1179 (2013).

${ }^{16}$ P. A. Premkumar, M. Toeller, I. P. Radu, C. Adelmann, M. Schaekers, J. Meersschaut, T. Conard, and S. V. Elshocht, ECS J. Solid State Sci. Technol. 1, P169 (2012).

${ }^{17}$ X. Lv, Y. Cao, L. Yan, Y. Li, and L. Song, Appl. Surf. Sci. 396, 214 (2017).

${ }^{18}$ V. P. Prasadam et al., Mater. Today Chem. 12, 396 (2019).

${ }^{19}$ R. Matero, A. Rahtu, M. Ritala, M. Leskelä, and T. Sajavaara, Thin Solid Films 368, 1 (2000).

${ }^{20}$ R. G. Gordon, D. Hausmann, E. Kim, and J. Shepard, Chem. Vap. Deposition 9, 73 (2003).

${ }^{\mathbf{2 1}}$ L. Henn-Lecordier, M. Anderle, E. Robertson, and G. W. Rubloff, J. Vac. Sci. Technol. A 29, 051509 (2011).

${ }^{22}$ H. Salami, A. Poissant, and R. A. Adomaitis, J. Vac. Sci. Technol. A 35, 01B101 (2017).

${ }^{23}$ M. Currie, M. A. Mastro, and V. D. Wheeler, J. Vis. Exp. 135, e57103 (2018).

${ }^{24}$ M. Pan, J. Liu, H. Zhong, S. Wang, Z.-F. Li, X. Chen, and W. Lu, J. Cryst. Growth 268, 178 (2004).

${ }^{25}$ P. Schilbe, Phys. B 316, 600 (2002).

${ }^{26}$ E. R. Cleveland, L. Henn-Lecordier, and G. W. Rubloff, J. Vac. Sci. Technol. A 30, 01A150 (2012).

${ }^{\mathbf{2 7}}$ A. I. Aria, K. Nakanishi, L. Xiao, P. Braeuninger-Weimer, A. A. Sagade, J. A. Alexander-Webber, and S. Hofmann, ACS Appl. Mater. Interfaces 8, 30564 (2016).

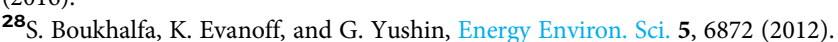

${ }^{29} \mathrm{~T}$. Watanabe, S. Hoffmann-Eifert, L. Yang, A. Rüdiger, C. Kügeler, C. S. Hwang, and R. Waser, J. Electrochem. Soc. 154, G134 (2007).

${ }^{30}$ T. J. Larrabee, T. E. Mallouk, and D. L. Allara, Rev. Sci. Instrum. 84, 014102 (2013).

${ }^{31}$ A. P. Peter et al., Adv. Funct. Mater. 25, 679 (2015).

${ }^{32}$ See supplementary material at https://doi.org/10.1116/6.0000152 for details of the chamber pressure profiles and the calculation of dose for pulses in multiple pulsing mode. 